\title{
English Language and Mathematics Mock Results as Predictors of Performance in SSCE Physics
}

\author{
Francis A. Adesoji \\ Department of Teacher Education, University of Ibadan, Ibadan, Nigeria \\ E-mail: francisadesoji@yahoo.com
}

KEYWORDS Mock results; english; mathematics; predictors; physics; performance

\begin{abstract}
The study was conducted to find out whether the performances of students in the SSCE in Physics could be predicted from their grades in English and Mathematics at the 1998 mock examination. Results of 150 students in five Secondary Schools in Lagos State were collected and analysed using regression analysis. Results indicated that performances of students in Mathematics could be used to predict results of SSCE Physics. It was however found that, results in English Language alone had low predictive values for performance in Physics. The author suggested that credit pass in English language should not be made mandatory for students seeking admission for science and applied science.
\end{abstract}

\section{INTRODUCTION}

Understanding of many scientific concepts poses problems for many of our students whose background in English Language is very poor. In some cases, passages are translated into vernacular before many of the pupils could understand them. This assertion is buttressed by the West African Examinations Council Chief Examiner's reports on the Senior School Certificate Examination May/June 1997, which states that:

The performance of candidates in English Language has been steadily deteriorating in the recent past. The main cause of this downward trend may be traced to inadequate preparation of the candidates by the school. For instance, most of the weaknesses in Part A (Essay) include:

(i) The inability to spell or punctuate correctly

(ii) Incorrect grammar

(iii) The ignorance of the difference between a sentence and phrase

(iv) The inability to express ideas correctly in English

(v) Immature vocabulary and the use of wrong words out of context P. 4

Researchers in English language (e.g. Adesanoye, 1973; Ayodele, 1981 and 1984) have shown that, the performances of pupils in the English Language are fast deteriorating, in a corresponding manner to their level of achievement in formal education. Some researchers (Akintola, 1985 and Adesoji, 1997), have also asserted that abilities in English Language do influence knowledge of students in other subjects in the curriculum.
Physical sciences like Physics cannot do without Mathematics. Many of the expression used in these subjects are borrowed from Mathematics. According to Ale (1981), a lot of evidence shows a strong association between Mathematics and development of science and technology. Adesoji (1999) was of the opinion that the bedrock of the physical sciences such as chemistry and physics is mathematics. Most experiments in physics involve the drawing of graphs and any student who intends to be proficient in physics must possess a strong background in mathematics. Unfortunately, a lot of problems exist with the teaching of mathematics at the secondary school level. Adepoju (1991) describes the approach used by many teachers of mathematics as one, which does not give room for students to develop their intuition, imagination and creative abilities. Adedayo (1994) gave empirical evidence of the incompetence of teachers of Further mathematics.

Secondary education in Nigeria is associated with a declining trend in students' enrolment and achievement in physics (Iroegbu, 1998; Orji, 1998). This situation is not likely to be peculiar to Nigeria as it depicts the general trend worldwide. Also, report by WAEC and JAMB continued to show that performances of students in physics had been on the decline for quite some years now. According to WAEC Chief Examiner's report (1997), some of the weaknesses noticed in the candidates in physics in the SSCE are:

(i) inability to express ideas logically and in clear terms

(ii) lack of adequate knowledge of fundamental of physics and

(iii) lack of calculative skills P. 136. 
It could be observed from this report that, beside lack of knowledge of the subject by the candidates, there are problems of English Language and Mathematics. The focus of this paper therefore is to find out whether ability of students in physics could be predicted from their knowledge of English Language and Mathematics.

\section{Purpose of the Study}

The study is out to find out whether one could explain performances of students in physics from their grades in English Language and Mathematics at the mock examination.

\section{Research Questions}

Based on the above objectives, the following questions were answered:

1. Are there positive relationship between English language, Mathematics and Physics?

2. Which of the independent variables (English language and Mathematics) better predicts performance in Senior School Certificate Examination (SSCE) in Physics?

\section{METHOD}

Research Design: The study is a survey research design using the ex-post facto type. This is because data were collected from the existing school records and this does not require the manipulation of independent variables.

Population and Sampling Procedure: The target population for the study was all the Senior School Certificate Candidates who offered Physics, English Language and Mathematics in 1998 May/June WAEC conducted examination in Lagos State, Nigeria.

The sample was made up of one hundred and fifty students who were randomly selected from five secondary schools in Shomolu and Mainland Local Government Areas of Lagos State. Thirty students were selected from each school to make up the sample using stratified sampling method. Seventy-four of the sample were females while seventy-six were males.

Data Collection: The collection of data for the study was made by the researcher who went round the selected schools to collect the final Senior School Certificate Examination results of the candidates in Physics in the 1998 academic year and their mock results in English Language and Mathematics in the same year. The results were collated for analysis.

Analysis of Data: This involved the use of stepwise multiple regression (backward procedure) to examine the relationship between the two independent variables (English Language and Mathematics) and the dependent variable (Senior School Certificate Examination grades in Physics).

\section{RESULTS}

The multiple correlation of physics with weighted combination of English Language and Mathematics is 0.91112 . The two independent variables also account for $83.0 \%$ of the variance of the dependent variable $\left(\mathrm{R}^{2}=0.8301\right)$. The remaining $17 \%$ is said to be residual and this could be due to error and other factors not investigated. However, the $\mathrm{R}^{2}$ of the variables is statistically significant $(F=359.22)$. This result answers the first question.

It could be observed from the results in Table 3 that the partial correlation coefficient (B) for English

Table 1: Correlation matrices of the three variables $(\mathbf{N}=150)$

\begin{tabular}{llll}
\hline & Physics & English & Mathematics \\
\hline Physics & 1.000 & 0.896 & 0.911 \\
English & 0.896 & 1.000 & 0.983 \\
Mathematics & 0.911 & 0.983 & 1.000 \\
\hline
\end{tabular}

Table 2: Composite effects of the independent variables (English Language and Mathematics) on SSCE Results in Physics

\begin{tabular}{llllll}
\hline Multiple $R$ & $R 2$ & Adjusted $R 2$ & S.E. & F-Ratio & Sig. F \\
\hline 0.91112 & 0.83014 & 0.82783 & 0.94172 & 359.22 & $0.0000^{*}$ \\
\hline * Significant at $\mathrm{P}<0.05 \mathrm{DF}=2.147$ &
\end{tabular}

* Significant at $\mathrm{P}<0.05 \mathrm{DF}=2,147$

Table 3: Relative effects of the independent variables (Mock Results in English and Mathematics) on students' performance in SSCE in Physics

\begin{tabular}{lllllll}
\hline Independent variables & $B$ & S.E.B & Beta & S.E. & $T$ & Sig. T \\
\hline Mathematics & 0.7762 & 0.1600 & 0.8962 & 0.1848 & 4.850 & $0.0000 *$ \\
English & 0.0152 & 0.1862 & 0.0151 & 0.1848 & 0.0828 & 0.9348 \\
(Constant) & 2.1247 & 0.2164 & & & 9.816 & 0.0000 \\
\hline
\end{tabular}

*Significant at $\mathrm{P}<0.05$ 
Table 4: Effects of Mathematics on student's performance in SSCE in Physics

\begin{tabular}{llllll}
\hline Multiple $R$ & $R 2$ & Adjusted $R 2$ & S.E. & F-Ratio & Sig. F \\
\hline 0.91112 & 0.83014 & 0.8289 & 0.9385 & 723.29 & $0.0000^{*}$ \\
\hline
\end{tabular}

* Significant at $\mathrm{P}<0.05$

Table 5: Relative effect of Mathematics on students' performance in SSCE in Physics

\begin{tabular}{lllllll}
\hline Independent variables & $B$ & S.E.B & Beta & S.E. Beta & $T$ & Sig. T \\
\hline Mathematics & 0.78911 & 0.02934 & 0.91112 & 0.3388 & 26.894 & $0.0000 *$
\end{tabular}

has T-value, which is statistically not significant (probability exceeds 0.05). Therefore, English will not be entered into the equation because only the independent variable with significant T-value will significantly predict students' performance in SSCE in physics (dependent variable). This independent variable is Mathematics. This answers the second question. If English language is ignored, the regression equation could be written by making use of the contribution of only Mathematics.

$$
\begin{aligned}
\text { WhereY } & =\text { SSCE result in Physics } \\
\mathrm{X} & =\text { Mock result in Mathematics } \\
\mathrm{Y} & =2.12+0.7762 \mathrm{X}
\end{aligned}
$$

The results in Table 4 further established the fact that it was mathematics that could be used to predict results of students in SSCE in physics. The value of $\mathrm{R}^{2}$ obtained after removing English showed no difference from the value obtained when the two independent variables (English and Mathematics) were employed in the equation. This implies that English does not contribute to the variance of the dependent variable (Physics).

\section{DISCUSSION}

The findings of this study indicated that results of students in Mathematics could be used to predict their results in Physics. Results in English Language were found to be irrelevant as far as predicting students' results in physics is concerned. It is a well-known fact that Mathematics is very useful for the understanding of physical science such as physics. The findings has also challenged the undue emphasis we lay on English for students opting for courses in the area of science and applied science. In this case, it should not be mandatory for science students to get a Credit Pass in English Language at the SSCE before they are admitted for Science and related courses in higher institutions of learning.

It should be realized that scientific facts and principles do not require the knowledge of laws governing grammar before one could understand them. Mathematics is an essential ingredient for
Physics. In the light of this, teachers of Mathematics would need to be more serious in teaching the subject because of its importance to science and consequently for technological development of the nation.

\section{REFERENCES}

Adesoji, F.A. 1997. “Correlates of students' academic performances in Biology with those of Mathematics and English Language: Implication for Counseling." Nigeria Journal of Counseling Education, 1(1): 74-76.

Adesoji, F.A. 1999. "Mock Examination results and students' gender as correlates of performances in the Senior School Certificate Examinations in Mathematics." African Journal of Educational Research, 5(1): $101-107$.

Adedayo, C.A. 1994. "Mathematical Competence of teachers of identified difficult concepts in further Mathematics." Paper delivered at Science Teachers' Association of Nigeria (STAN) Conference, Abeokuta, August, 1994.

Adepoju, J.A. 1991 "Factors and Problems in the teaching and learning of Mathematics in Nigeria Secondary Schools." National School Curriculum Review Conference. Kaduna, 2nd - 6th September, 1991.

Adesanoye, F. 1973. A Study of Variables of Written English in Nigeria. Unpublished Ph.D. Thesis, London: University of London.

Akintola, A. cited from Adegbite Wale. 1988. "The relationship between students' performances in English Language and other Secondary School subjects in Nigeria." Journal of Educational Research and Evaluation, 1 (2): 200-204.

Ayodele, S.O. 1981. An Evaluation of the Level of Oral English Performances of Grade Two Teachers' Trainees. Unpublished Ph.D. Thesis, Ibadan: University of Ibadan.

Ale, S.O. 1981. "Mathematics in Science and Technology. A Preamble." The Proceedings of the Mathematical Association of Nigeria. August, 14-26.

Iroegbu, T.O. 1998. Problem-Based Learning Numerical, Ability and Gender as Determinants of Achievements, Problem-Solving and Line-Graphing Skills in Senior Secondary Physics in Ibadan." Unpublished Ph.D. Thesis, Ibadan: University of Ibadan, Nigeria.

Orji, A.B. 1998. "Effects of Problem-solving and Concept-Mapping Instructional Strategies on Students' Learning Outcomes in Physics. Unpublished Ph.D. Thesis Ibadan: University of Ibadan.

West African Examination Council (WAEC). 1997. Chief Examiner's Reports. Lagos: WAEC. 